\title{
Ocorrência de infecção múltipla por Babesia canis, Hepatozoon canis e Haemobartonella canis, em um cão esplenectomizado
}

\section{Occurence of multiple infection with Babesia canis, Hepatozoon canis and Haemobartonella canis in a splenectomized dog}

\author{
Lucia Helena O'Dwyer'1 , Lanassa Guimarães², Carlos Luiz Massard ${ }^{3}$
}

\section{Resumo}

Um cão esplenectomizado, naturalmente infectado com Hepatozoon canis, foi inoculado via intravenosa com sangue positivo para Babesia canis. Após a inoculação, além dos dois protozoários, foram observadas formas cocóides, e em cadeia, de Haemobartonella canis na superfície dos eritrócitos. O aparecimento deste último pode ter ocorrido em função da inoculação ou da supressão imunológica causada pelos outros dois agentes.

Palavras chave: Babesia canis; Hepatozoon canis; Haemobartonella canis; cão

São vários os agentes patogênicos transmitidos ao cão pelo carrapato Rhipicephalus sanguineus e que podem estar associados (Neitz, 1939; Ewing, 1965; Wright, 1971). No presente trabalho um cão, sem raça definida, esplenectomizado, apresentou infecção natural por Hepatozoon canis (Fig. 1A) do mesmo modo que outros quatro cães da mesma ninhada. Os gametócitos de $H$. canis apareciam na circulação esporadicamente em parasitemias discretas. $O$ animal estudado foi inoculado via intravenosa com sangue infectado por Babesia canis, passando a apresentar este protozoário nos esfregaços sangüíneos quatro dias depois da inoculação. Além de $B$. canis (Fig. 1B), foram observadas formas cocóides, em anel e em cadeia, de Haemobartonella canis (Ha. canis) (Fig. 1C) na superfície dos eritrócitos. Onze dias após a inoculação, $H$. canis voltou a aparecer na circulação, tornando-se constante a partir de então. O diâmetro das formas cocóides de $H$ a. canis variou de 0,3 a 0,7 $\mu \mathrm{m}$, com uma média de $0,4 \pm 0,13 \mu \mathrm{m}$ e as formas em anel variaram de 0,5 a 0,8 $\mu \mathrm{m}$, com uma média de 0,6 $\pm 0,1 \mu \mathrm{m}$.

Os gametócitos de $H$. canis mediram de 4,32 a 5,85 $\mu \mathrm{m}$ no seu diâmetro menor e 8,82 a $11,52 \mu \mathrm{m}$ no maior, com uma média de $5,11 \pm 0,57 \times 9,56 \pm 1,13 \mu \mathrm{m}$.

A origem do parasitismo por $\mathrm{Ha}$. canis pode ter sido o sangue do doador, apesar deste nunca ter apresentado esta riquétsia, ou então, o cão já era portador e com a queda de resistência devido aos outros hemoparasitos esta foi reativada. As mensurações das formas de $\mathrm{H}$. canis e Ha. canis estão de acordo com a literatura (Wright, 1971; Massard, 1979). No Brasil, a Ha. canis já havia sido assinalada por Massard et al. (1978) e Biondini et al. (1983); contudo, essa é a primeira descrição da infecção concomitante destes três agentes em um único cão.

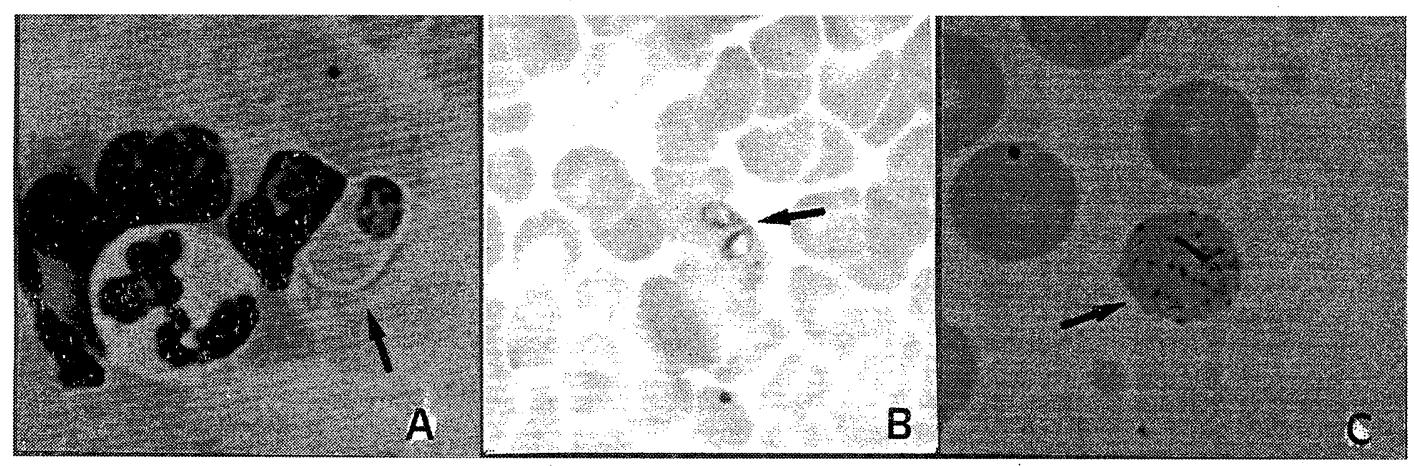

Figura - Esfregaços sangüíneos de cão apresentando: (A) forma gametocítica intraleucocitária de Hepatozoon canis, (B) forma intra-eritrocítica de Babesia canis e (C) forma eritrocitária de Haemobartonella canis. Giemsa $(-=10 \mu \mathrm{m})$.

\footnotetext{
Trabalho realizado sob os auspícios da CAPES/CNPq.

1 Curso de Pós-Graduação em Medicina Veterinária - Parasitologia Veterinária, IB, Universidade Federal Rural do Rio de Janeiro (UFRRJ), km 47 da Antiga Rodovia Rio São Paulo, 23851-970 Seropédica, RJ, Brasil

${ }^{2}$ Bolsista de Iniciação Científica, CNPq

${ }^{3}$ Departamento de Parasitologia Animal, IB, UFRRJ
} 


\section{Abstract \\ Occurence of multiple infection with Babesia canis, Hepatozoon canis and Haemobartonella canis in a splenectomized dog}

A splenectomized dog, naturally infected with Hepatozoon canis, was intravenously inoculated with blood infected with Babesia canis. After the inoculation Haemobartonella canis (Ha. canis) was also diagnosed. The occurence of $\mathrm{Ha}$. canis might be due to direct transmission from the donor or immunossupression of the recipient dog.

Key words: Babesia canis; Hepatozoon cani; Haemobartonella canis; dog

\section{Referências bibliográficas}

Biodini J, Lopez ZO, Viana FAB, Araújo T 1983. Diagnóstico laboratorial de Haemobartonella canis em Belo Horizonte, MG. Arq Bras Med Vet Zoot 35 (5): 743-744.

Ewing SA 1965. Methods of reproduction of Babesia canis in erythrocytes. Am J Vet Res 26(112): 727-733.

Massard C de A 1979. Hepatozoon canis (James, 1905) (Adeleida: Hepatozoidae) em cães do Brasil, com uma revisão do gênero em membros da ordem carnívora. Tese Mestrado em Medicina Veterinária-Parasitologia Veterinária, Universidade Federal Rural do Rio de Janeiro, Rio de Janeiro, $121 \mathrm{pp}$.

Massard CL, Rezende HEB, Massard C de A, Serra Freire NM 1978. Observações sobre Haemobartonella canis (Kikuth, 1928) (Microtatobiotes: Rickettisiales) em canídeos domésticos no Estado do Rio de Janeiro. Anais II Congresso da Sociedade Brasileira de Parasitologia, João Pessoa, PB.

Neitz WO 1939. The appearence of Bartonella canis in a dog suffering from Rickettsia canis. SAVMAX(3): 103-105.

Wright IG 1971. The isolation of Haemobartonella canis in association with Babesia canis in a splenectomised dog. Aust Vet J 47(4): 157-159. 